\title{
Electricity regulation and economic growth
}

Costa-Campi, M.T., Department of Economics and Chair of Energy Sustainability, Barcelona Institute of Economics (IEB), University of Barcelona, Spain. E-mail: mtcosta@ub.edu

García-Quevedo, J., Department of Economics and Chair of Energy Sustainability, Barcelona Institute of Economics (IEB), University of Barcelona, Spain. E-mail: jgarciaq@ub.edu (corresponding author)

Trujillo-Baute, E., Department of Economics and Chair of Energy Sustainability, Barcelona Institute of Economics (IEB), University of Barcelona, Spain. E-mail: elisatrujillo@ub.edu

\begin{abstract}
The main objective of this paper is to analyse the effect of electricity regulation on economic growth. Although the relationship between electricity consumption and economic growth has been extensively analysed in the empirical literature, this framework has not been used to estimate the effect of electricity regulation on economic growth. Understanding this effect is essential for the assessment of regulatory policy. Specifically, we assess the effects of two major areas of regulation, renewable energy promotion costs and network costs, on electricity consumption and growth. A dataset for the period 2007-2013 and 22 European countries was compiled based on CEER reports and EUROSTAT databases. The results of the empirical analysis show that the two regulation instruments have a negative effect on electricity consumption and economic growth and provide estimates of their effects on growth in quantitative terms.
\end{abstract}

Keywords: electricity regulation, network costs, renewable energy, GDP 


\section{INTRODUCTION}

In the last decade it has become evident that the energy sector is at a turning point, a new model is required to face the challenges of the upcoming years. The required transformation of the traditional energy model, especially with regard to environmental effects, has led to an inevitable and profound regulatory reform. From a regulatory perspective, the energy sector has witnessed a high level of activity at the European level. Three consecutive packages were adopted aiming at harmonising and liberalising the European Union (EU) internal energy market. In addition, the climate and energy package set ambitious targets for 2020 in terms of emissions reduction, penetration of renewables and energy efficiency. Climate and energy as an integrated policy within the EU has led to the trilemma of targets: competitiveness, sustainability, and security of supply. More recently, the European Commission has defined the 2050 roadmap and the 2030 targets as an intermediate step in energy and climate policy to achieve sustainable economic growth.

Unfortunately, the objectives pursued by the climate and energy policy of the EU -environmental sustainability, security of supply and competitiveness- are difficult to achieve simultaneously and even more if they are supported by market forces only. Therefore, priorities need to be set. When the energy policy objectives are analysed in detail, it becomes apparent that the environmental dimension has played an important role. Nevertheless, the economic crisis and its undesirable effects on the capacity of European economies to grow and create wealth, has increased the attention on competitiveness as one of the main concerns in policy agenda. It is fundamental for industrial development and economic growth that European firms preserve or improve their competitiveness. Within this context -and keeping in mind the other energy policy objectives, since firms must compete in difficult environments-, the basic question is on the role of energy in operating costs and competitiveness.

The increasing concern in Europe about the recent evolution of energy costs and prices and its impact on industrial competitiveness is evident in the 2014 EU Communication 'For a European Industrial Renaissance'. Every day there is greater need to secure an affordable access to energy and raw materials, since these are an important part of the costs in many industries. As the evolution of energy costs negatively influences the competitiveness of energy intensive industries, it is fundamental to avoid disproportionate increases of those costs as a consequence of taxes, levies or other instruments introduced by Member States to enforce various policies. This is essential to guarantee a cost-effective relationship and contributes to an improvement in EU competitiveness. Therefore, the assumption of the upcoming objectives must follow a cost 
effective approach -affordable and competitive-, ensuring security of supply and sustainability, while taking into account the current economic and political context.

The main objective of this paper is to analyse the effect of electricity regulation on economic growth. Understanding this effect is deemed essential for the assessment of regulatory policy. Specifically, we assess the effects of two major regulations, renewable energy promotion costs and industrial network cost, on electricity consumption and gross domestic product (GDP). In this analysis we assume that this impact takes place though the influence of regulation on electricity consumption.

To carry out the empirical estimation, a database for the period 2007-2013 and 22 European countries has been compiled based on the EUROSTAT database and Council of European Energy Regulators (CEER) reports. The information for 22 countries and over 7 years allows us to have an appropriate panel of data. The contributions of this paper to the literature are as follows. First, instead of analysing the effects of regulation on economic growth directly, we use a system of two equations to take into account the fact that electricity regulation potentially affects economic growth through its impact on electricity consumption. This procedure helps to improve our understanding of the mechanisms regarding the effects of electricity regulation on growth. Second, many papers focus on only one specific instrument. Instead, we consider the two main regulatory instruments, renewable energy promotion costs and network costs so their effects can be compared. Third, to include both instruments has required the construction of a novel and comparable measure of renewable promotion costs for 22 European countries.

The rest of the paper is organised as follows. Section 2 provides the background on the link we explore later in the empirical exercise between regulation, electricity consumption and economic growth. In Section 3 the model, variables and methods are described in detail. Section 4 details and discusses the results of the empirical analysis. Finally, Section 5 provides the conclusions and policy implications derived from the analysis performed.

\section{BACKGROUND: REGULATION, ELECTRICITY CONSUMPTION AND ECONOMIC GROWTH}

Notwithstanding its relevance for the analysis of regulatory policies, the academic literature has devoted, with very few exceptions (Hudson and Jorgenson, 1974), little attention to the relationship between electricity regulation and economic growth. This is mainly attributable to the fact that this relationship is not a direct one, but rather it is mediated through the effect that 
regulation has on the consumption of electricity. The mechanism at work in this relationship is the following; electricity is an economic factor of great relevance since it is a key input in the modern production process, its consumption having a significant impact on a company's production costs and, hence, on economic growth. Next, we provide background and fundamentals for our model based, first, on the link between regulation and electricity consumption, and second, on the relationship between electricity consumption and economic growth.

\subsection{Regulation and electricity consumption}

This research starts from the assumption that the price system is a useful mechanism to transmit relevant information which has an impact on consumer behaviour, within the European context. Whether a depletion of an existing resource, an increasing scarcity of a non-renewable energy or an arbitrage opportunity in a particular market, all the relevant information is usually transmitted through the price, through variations in price levels that make agents react to the fluctuations by changing, for instance, their consumption.

The electricity sector is characterised by being one of the most highly regulated sectors. In the framework of liberalisation, being pushed forward in January 1997 with the publication of EC Directive 96/92/EC of 19 December, the regulatory changes affecting the electricity sector have been especially intense and have had an enormous impact on the structure of the sector and its business agents, as well as on the functioning of the electricity market itself.

Within this process, the regulatory function appears as a key element, being responsible for the definition of the framework that guarantees the correct technical management of the power system, the coordination of the networks and the transparency of access conditions for all the agents participating in the power market. In other words, in this process of liberalisation, competition and regulation represent two sides of the same coin. Real competition in power markets cannot be fully achieved without ensuring non-discriminatory network access and market functioning at the wholesale and retail levels. Economic regulation must guarantee the recovery of all regulated costs in order to ensure the economic viability of the power system. In this context, energy regulation has a significant economic impact, which has to be considered exante when designing energy policy initiatives.

Evaluating the economic impact of the regulation of the electricity sector and of the changes in these regulations is a complex task. The assessment and measurement of the impact of the 
reform processes and regulatory changes have been analysed in the relevant literature through various general approaches.

The first is a macroeconomic approach focusing on the analysis of regulatory policies and their impact within the framework of general equilibrium theory (Chisari and Estache, 1999). Contributors using this approach constructed general equilibrium models in an attempt to capture first- and second-order effects to establish, identify and quantify transmission mechanisms and the overall effects of a specific regulatory policy or measure on economic growth, through the modelling of the behaviour of economic agents. The analysis of the impact of regulatory policies with general equilibrium models is intuitively attractive as it allows the quantification of both direct and indirect economic effects. However, these models are characterised by enormous complexity and the constraints placed on any formulation, implementation and description, given the need to simplify the hypotheses governing transmission mechanisms. This limitation undermines their use when the aim is to analyse the impact of specific actions in the regulatory domain.

The second approach has involved the quantitative evaluation of a country's regulatory framework. This provides a better understanding of the risks, particularly the regulatory ones. Such an evaluation of the regulatory framework is useful in a number of ways: it enables comparisons to be made; it identifies possible improvements; and it facilitates the evaluation of the impact of implementing new measures. The evaluation is not without its difficulties, however (Becker, 2009) since it requires access to measurable parameters that allow for an analysis of their evolution over time as well as a comparative analysis of regulatory frameworks.

Given that all regulatory actions seek to achieve a significant improvement in the provision of an electric power supply, a third set of studies has attempted to assess the effects of regulatory changes based on the measurement and evaluation of outcomes - the so-called performance metrics approach - in terms of price, accessibility, quality and efficiency in the provision of the service (Cubbin and Stern, 2006; Pollitt, 2009). This approach has been widely used in academic studies to evaluate the impact of regulatory changes based on the results obtained in terms of pricing, consumption, investment, service quality or the evolution in greenhouse gas emissions, among others. The simplicity of this approach is both its main limitation and advantage. The main limitation is that, been essentially an approach to evaluate -ceteris paribus- direct effects on output metrics, it does not allow for the evaluation of multiple indirect effects. At the same time, the simplicity of this approach is its main advantage over the first two approaches. Unlike the quantitative evaluation of a country's regulatory framework, the performance-metric approach 
does not require access to the countries detailed regulatory frameworks and their evolution. The greatest advantage of the performance-metric over the general equilibrium models is that it does not require detailed hypotheses on all the transmission mechanisms mediating the effects that have been analysed. Therefore, the results of the total effects on performance metrics are not dependent on those hypotheses.

Taking into account the limitations of the first two approaches, the general framework provided by the third approach has been used in this paper. This framework is deemed suitable to address the issues raised in the introduction as well as to capture the flexibility required by the diversity of contexts in which the effect of electricity regulation is to be assessed. Several regulatory variables have been considered as key drivers of electricity consumption, the focus of this paper is on the two specific regulated components of the electricity retail price. This choice is motivated by their weight in the retail electricity price, and consequently, the potential relevance of their impact on electricity consumption. On average for the 22 European countries included in our sample, during the period 2007-2013 the promotion costs related to the support for RES-E and the network costs represented respectively $11 \%$ and $23 \%$ of the retail price faced by industrial consumers (own calculations based on Eurostat and CEER). In the context of this study, given that the mechanism through which regulation affects consumption is via the regulated components of the retail price, a negative relationship is expected between the regulatory variables and electricity consumption.

\subsection{Electricity consumption and growth}

The relationship between electricity consumption and economic growth has been extensively analysed in the empirical literature. Understanding the links and the direction of causality between these two variables has important implications for the design of energy and environmental policies.

As recent reviews of the literature show (Payne, 2010; Otzurk, 2010), in spite of the huge number of contributions to the analysis of the relationship between electricity consumption and growth there is not a consensus with respect to the direction of the effects nor the magnitude of that effect. This lack of consensus in the empirical literature is due to the differences in energy consumption patterns, different countries characteristics regarding their stage of development, and institutional aspects, heterogeneity in climate conditions and the time period chosen for the studies (Payne, 2010; Ozturk, 2010). 
The multiplicity of results gives support to different hypotheses. More specifically, this relationship can be synthesized into four testable hypotheses (Payne, 2010):

The first one, in the context of a Granger-causality approach, is "the growth hypothesis". This hypothesis is based on the idea that energy, together with labour and capital, is a main driver of economic growth. It is supported if an increase in energy consumption causes an increase in the real gross domestic product (GDP). A main policy implication would be that energy conservation policies could have a negative effect on economic growth

On the other hand, "the conservation hypothesis" is supported if an increase in real GDP causes an increase in energy consumption. This would imply that energy conservation policies, such as greenhouse emission reductions, efficiency improvement measures or management policies whose aim is to reduce energy consumption would not adversely affect real GDP.

Regarding the third theory, "the neutrality hypothesis", the absence of Granger-causality is assumed. Energy consumption is regarded as a small component of real GDP or it is not correlated with GDP and therefore its change should not have a significant impact on economic growth. In this case, energy policies are not expected to affect economic growth.

Finally, "the feedback hypothesis", suggests that energy consumption and real GDP are jointly determined and may serve as complements to one another. This approach is supported statistically when there is evidence of bi-directional Granger-causality. Again, policies that foster efficiency in energy consumption may not adversely affect real GDP.

To sum up, the literature review suggests that, whereas a negative effect of energy regulation on electricity consumption can be expected, the final effect on economic growth is not conclusive and it is a matter of empirical analysis. The surveys of the empirical literature on the electricity consumption-growth nexus have emphasized the convenience of using multivariate models and to support the empirical analysis on well-established theoretical frameworks to include all the relevant control variables. Therefore, our empirical estimations are based on the theory of economic growth (Solow, 1956; Romer, 1990) that provides a formal framework for the analysis of the determinants of growth and the ensuing effects on electricity consumption.

In this framework, a conventional neoclassical production function, we include together with electricity consumption the stock of capital and employment, the two main inputs of production. Therefore, we treat them as separate inputs with the purpose of analysing the relationship between electricity consumption and an aggregate measure of output, such as gross domestic 
product. This relationship can be affected, like energy use, by substitution between energy and other inputs, technological change, shifts in the composition of outputs and also by shifts in the mix of other inputs (Stern, 2011). This augmented function has been used in many analyses with electricity or energy consumption to estimate the causal relationship between energy consumption and growth and to avoid an omitted variable bias issue (Stern, 1993 and 2000; Apergis and Payne, 2010). ${ }^{1}$

\section{MODEL, VARIABLES AND METHODS}

The approach to estimate the impact of electricity regulation on growth is based on the theory of economic growth and on the relationship between electricity consumption and growth. In the framework of growth theory, the contribution of production factors to economic growth is analysed. In our empirical strategy we go one step further than the more traditional literature performing time-series analysis on the relationship between growth and electricity consumption (e.g. cointegration ${ }^{2}$ ). By means of a multivariate panel-regression modelling, we have better control of potential omitted variables and make the most of the panel dimension in our database. In our empirical analysis it is assumed, as has been pointed out above, that electricity regulation potentially affects economic growth through its impact on electricity consumption.

Therefore, we use a system of two equations that is estimated in two stages. The first stage of the econometric model captures the impact of electricity regulation on electricity consumption, controlling for the other observable factors that affect this consumption (Eq. 1). In particular, our purpose is to analyse the effects of renewable energy promotion costs and industrial networks costs. The second stage captures the impact of electricity consumption (the estimated value from the first stage) on economic growth, controlling for the other observable factors of production (capital and employment) which have a direct impact on economic growth (Eq. 2).

\footnotetext{
1 The relationship between growth and electricity consumption has also been shown with other approaches. Henderson et al. (2012) analyse the usefulness of using satellite data on night lights as a proxy for economic activity and shows that light growth is a very useful proxy for GDP growth.

${ }^{2}$ Regarding this relationship, two or more cross-sectional time series are cointegrated if they share a common stochastic drift, and only integrated variables can be cointegrated. We performed two tests, the augmented Dickey-Fuller (ADF) test (Dickey and Fuller, 1979) and the Phillips-Perron (PP) test (PhillipsPerron, 1988), both under the null hypothesis of a unit root (integration of first order). The results for both tests confirmed that the series were not integrated in levels and, hence, that it was not necessary to test for cointegration (see Table A1 in appendix).
} 


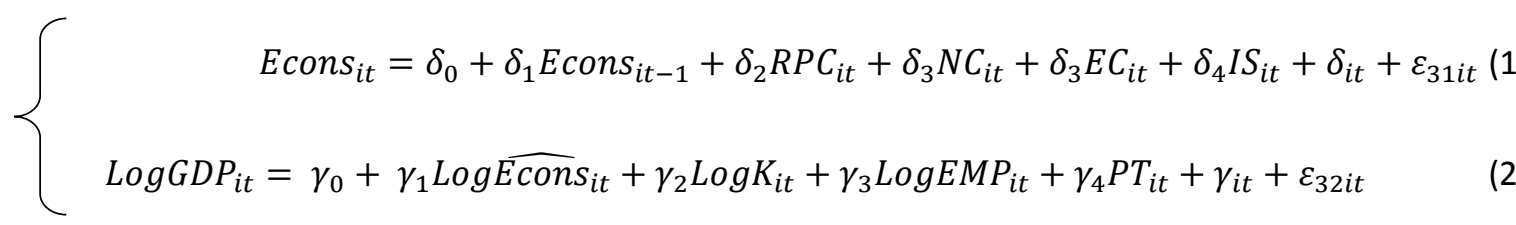

where a full description of the variables and its sources are provided in Table 1. In order to carry out the empirical estimation, a dataset for the period 2007-2013 and 22 European countries has been compiled based on EUROSTAT database and CEER reports. The information for 22 countries and 7 years allows us to have an appropriate panel of data in order to apply panel-data models, which have substantial advantages with respect to estimation techniques which use cross-section data, including the capacity to control for individual heterogeneity, a greater degree of freedom and a greater variability.

- INSERT TABLE 1 AROUND HERE-

The regulatory variable capturing the promotion costs related to the support for RES-E, Renewable Promotion Costs (RPC), is worth mentioning. Unlike all other variables used in this analysis, the information required to identify the impact of renewable electricity support costs is not directly available in a standardized public or private database. This novel variable, based on the information provided by the Council of European Energy Regulators reports (CEER 2011, 2013, 2015), was built as follows. First, the total expenditures on RES-E promotion were calculated as the product of the RES-E weighted average support level by technology (from CEER reports) multiplied by the overall RES-E production (from EUROSTAT). Then, the Renewable Promotion Cost (RPC) was calculated as the ratio between the total expenditure on RES-E promotion and the total electricity consumption (from EUROSTAT). Therefore, the resulting variable is measured in $€ / M W h$ units. This variable permits the degree of these regulated costs to be captured taking into account the size of the electricity system (in terms of MWh of electricity generation), which facilitates cross-country comparisons. Table 2 provides the summary of the descriptive statistics for this and the other variables used in this study.

- INSERT TABLE 2 AROUND HERE-

Table 3 contains the correlation matrix which provides relevant information on the relationship between the variables included in our model. This correlation matrix helped us to reject the presence of multicollineality which could arise if there was a high correlation between the 
explanatory variables. Therefore, it has been useful to develop the specification of the model to perform the empirical analysis.

- INSERT TABLE 3 AROUND HERE-

The empirical estimation is performed using the aforementioned database through the implementation of the following panel data econometric techniques. In the first stage, the consumption equation (Eq. 1) is estimated with the Arellano-Bond method for dynamic panel data. This allows us to avoid the potential bias coming from the endogeneity which a dynamic process generally features. The estimated values of electricity consumption, capturing the estimated effects of regulation (RPC and NC), are recovered and stored. In the second stage, the estimated values of the first stage are introduced into the growth equation (Eq. 2). It is then estimated with fixed effect panel data techniques.

\section{RESULTS AND DISCUSSION}

Tables 4 and 5 show the results of the estimations of the two equations used to assess the effects of the two regulations, renewable energy promotion costs and industrial network cost, on electricity consumption and GDP.

- INSERT TABLES 4 \& 5 AROUND HERE-

The results for the effects of the two regulations on electricity consumption and GDP show the expected negative sign, are statistically significant and their magnitudes are reasonable. In both cases we are assuming, as we explained in the description of the model, that the impact on GDP takes place through the effects on electricity consumption. Renewable promotion costs and network costs caused an increase in the electricity prices that, as our estimations show, have a negative effect on electricity consumption. Our results of the estimation of the growth equation support the "growth hypothesis" regarding the relation between electricity consumption and growth. This hypothesis is based on the assumption that energy, together with labour and capital, is a factor of production and a driver of economic growth. Therefore, the reduction of electricity consumption negatively affects economic growth with a decrease in GDP levels.

These estimations therefore allow for the assessment of these two regulatory instruments and give a proper estimation of their quantitative effects on levels of GDP. Nevertheless, our analysis focuses only on the direct effects of regulation on electricity consumption and GDP and does not 
consider other possible, indirect effects that, for instance, the promotion of renewable energies may have on technological innovation and potentially on economic growth.

The estimation of the elasticities regarding the effects of renewable energy promotion costs presented in Table 6 shows that an increase of $1 \%$ in these costs leads to a decrease of $0.03 \%$ in electricity consumption and a reduction of $0.006 \%$ in GDP which, in absolute terms, means a $28.6 \mathrm{M} €$ decrease. Departing from the assumption that there are not any additional regulatory changes during the period, the long-run elasticities are, as expected, lower, although only slightly than the short-term elasticities.

- INSERT TABLE 6 AROUND HERE-

The parameter of the estimations of the other regulatory variable, the network cost, are also negative (see Table 7). The estimations of the elasticities show that an increase of $1 \%$ in these costs leads to a decrease of $0.06 \%$ in electricity consumption and of $0.01 \%$ in GDP. In absolute terms this means a reduction of $55.8 \mathrm{M} €$. Again, long-term elasticities are slightly lower than the short-term.

\section{- INSERT TABLE 7 AROUND HERE-}

The comparison of both regulatory instruments shows that in relative terms the quantitative effects on GDP are higher for network costs than for renewable promotion costs. Nevertheless, caution is needed in this comparison because they are significantly different in monetary terms, with the effects from a $1 \%$ increase in network costs being higher than from a $1 \%$ increase in renewable promotion costs.

Besides, while a $1 \%$ increase in the network costs is on average equivalent to $0.29 € / \mathrm{MWh}$, the same increase in the renewables promotion costs is on average equivalent to $0.14 € / \mathrm{MWh}$. Therefore, when comparing the results from the two regulated variables, these are in line with the expectations, given the estimated elasticities and their average values.

Finally, the results corresponding to the control variables included in both equations, needed to avoid the omitted variables problem, and to ensure that we obtain causal relationships between regulatory variables and growth, are all statistically significant and show the expected signs. In the two estimations, corresponding to renewable promotion costs and network costs, the variables of the growth equation (employment, capital and productivity trend) have positive 
values. In addition, in electricity consumption a greater participation of energy intensive sectors has a positive effect on electricity consumption while higher energy costs have a negative effect

\section{CONCLUSIONS AND POLICY IMPLICATIONS}

This paper focuses on the effects of electricity regulation on economic growth through its impact on electricity consumption. Although there is an extensive literature analysing the relationship between energy consumption and economic growth, the analysis carried out in this paper introduces several novelties. First, to the best of our knowledge, there is no study that has estimated the specific effects of electricity regulation on economic growth, taking into account their effects on electricity consumption. Second, the paper considers two different instruments to disentangle the effects of regulation on growth: renewable promotion costs and network costs. Third, the renewable promotion costs have been calculated in a standardized way to allow crosscountry comparison.

In our analysis we have examined the relationship between electricity regulation and economic growth through the effect that regulation has on the consumption of electricity. In our estimations we have included other variables, such as the participation of intensive energy sectors or the stock of capital that may mediate this relationship. Nevertheless, in this analysis we have focused specifically on the potential effects of electricity regulation on growth. Although this is an important area, the linkages between electricity regulation and growth are complex and may be affected by different variables, such as investment in capital goods, in innovation, and also by different aspects of the behaviour of firms and consumers that would be convenient to take into account for a comprehensive analysis of these linkages. Despite these limitations, our analysis provides, as pointed out above some novelties and contributes to shed some light on the importance of well- designed electricity regulation and provides some relevant policy implications.

The main results of the analysis show, as expected, that the effect of regulatory cost on electricity consumption is negative. In addition, the final effect on economic growth according to the estimations of the empirical analysis, is also negative. Hence, an increase in the regulated cost leads to a decrease in electricity consumption and to a reduction of GDP. The empirical results support "the growth hypothesis" regarding the relationship between electricity consumption and economic growth. 
A main economic implication from these results is that any decrease in electricity consumption, through energy conservation policies, could have a negative effect on economic growth. Nevertheless, it should be pointed out that a reduction in energy consumption may allow for an increase in disposable income to be spent on other products and services positively affecting economic growth. In addition, there are other indirect effects that are not covered by our analysis, so it is necessary to be prudent with our conclusions. It should also be highlighted that this by no means contradicts some recent reports (i.e. IEA, 2016) which suggest that $\mathrm{CO} 2$ emissions are decoupled from economic growth at the world level. Taking into account that a close relationship between electricity consumption and growth is observed, increased decoupling of growth and $\mathrm{CO} 2$ emissions is possible if electricity demand is increasingly covered with RES-E (as suggested by IEA, 2016) or if CCS technologies improve.

In addition, there are regulatory implications, in the sense that any regulation increasing the price of energy will have a negative effect on economic growth. This is an important message for regulators and policy makers involved in the design of regulatory measures affecting prices. It also allows for the use of regulation as a tool to promote economic growth. This is in contrast to what is advocated by some authors in terms of the use of energy taxes on electricity prices as a superior option to promoting energy efficiency (Filipovic et al., 2015).

The effect of the regulatory cost on prices seems to indicate that a revision of the current framework is required. These results reinforce the need to search for market-based regulatory mechanisms that would potentially generate less disruption on prices. This idea is in line with the approach that has been taken by the EC in the most recent energy policy proposal package "Clean energy for all Europeans" (EC, 2016). The Commission sought to transform the energy regulatory framework, emphasising the predominant role that market-based instruments should have in this sector.

The changes implemented during recent years by several European countries in renewable promotion mechanisms are clear examples of an increasing market approach. Moving from Feedin Tariff to Feed-in Premium or to an auctioning system it is intended to reduce the burden on promotion costs. Another alternative in the case of renewable promotion cost is to avoid financing climate policy through the price of energy, for instance by using funds from the public budget. This would simultaneously profit society from the indirect benefits related to renewable deployment and innovation, while increasing potential growth through a direct effect on electricity prices. 
The case of network costs is more complex. Given their natural monopoly features, network costs are traditionally covered through regulated fees. An alternative approach could be to implement innovative solutions allowing for cost reductions, while keeping the competitiveness and investment levels of the companies that are managing the networks, hence, maintaining or increasing the quality of service. For instance, given the economic and environmental costs of electricity losses (Davi-Arderius et al. 2017), measures to decrease losses could reduce the impact on prices related to network cost. In this regard, some options include increasing efficiency in distribution network management through a more active role of DSOs or linking payments to the operator's ability to introduce innovation -for instance in the deployment of smart grids. In addition, higher network efficiency could be promoted in the transmission level encouraging the cross-border interconnection that is expected to increase price convergence as well as the number of players in the markets. Finally, measures that promote conveniently located Distributed Generation could help to solve grid congestion problems and partially avoid the new investment required.

From the results of the paper, we infer that electricity regulation needs some help to moderate the estimated negative impact that is caused to growth through prices. Policy makers should carefully assess the effects the existing and new regulation can have on growth. Furthermore, complementary policies that moderate those effects and are able to introduce additional economic incentive should be looked for.

To alleviate the impact on economic growth that lower energy consumption generates a series of policy measures needs to be undertaken to promote energy efficiency. The benefits of energy efficiency policies are multiple affecting everything from macroeconomic performance, environment and industry to energy prices (IEA, 2015). As is stated in the Energy Efficiency Directive proposal recently launched by the European Commission, energy efficiency is considered to trigger growth, job creation and investment (EC, 2016). In this sense, promoting energy efficiency will have positive spillovers on job creation and demand for new appliances and services creating an indirect impact on economic growth. For instance, one recent paper that explores the effects of energy efficiency on economic growth (Bataille \& Melton, 2017) shows increases in GDP, employment and welfare. In addition, promoting energy efficiency will allow for the decoupling of economic growth and energy consumption thereby reducing the energy intensity of the economy. Less energy needed per unit of output clearly helps to minimize the negative impact of regulation can have on energy prices and consequently on economic growth. 
However, governments should be cautious with policy implementation because energy efficiency could jeopardize the expected positive outcome through a rebound effect.

What may be concluded from this paper is that regulatory design should target an efficient allocation of resources, minimizing the effect on prices. Given the positive relationship between electricity consumption and economic growth found in this empirical study, a regulatory policy increasingly reliant on market mechanisms should be designed and implemented, in order to achieve the regional objectives for renewables, energy efficiency and $\mathrm{CO} 2$ reduction. These market mechanisms could be expected to contain regulatory costs to promote renewables -and other costs from policies aiming at energy efficiency or $\mathrm{CO} 2$ mitigation. In the case of networks there is potential for cost containment with the development of innovative regulatory solutions. Nevertheless, any regulatory change should not harm the competitiveness of the sector or its operators, and should not risk the achievement of the energy and environmental targets of European energy policy for 2030. Trade-offs between different goals are likely, however. 
Acknowledgments: We are grateful to Odín Costa for providing excellent research assistance. We are also very grateful for the suggestions and comments from two anonymous referees. We acknowledge financial support from the Chair of Energy Sustainability (IEB, University of Barcelona) and from the projects ECO2015-69107-R (MINECO / FEDER, EU) and 2015-SGR-531 (Government of Catalonia). 


\section{REFERENCES}

Apergis N., and Payne J. 2010. Renewable energy consumption and economic growth: Evidence from a panel of OECD countries, Energy Policy 38; 656-660.

Bataille, C., and Melton, N. 2017. Energy efficiency and economic growth: A retrospective CGE analysis for Canada from 2002 to 2012. Energy Economics 64, 118-130.Becker F. Calidad institucional y regulación económica, 2009.

CEER, 2011. Report on Renewable Energy Support in Europe. Council of European Energy Regulators. Ref: C10-SDE-19-04a. Brussels.

CEER, 2013. Status Review of Renewable and Energy Efficiency Support Schemes in Europe. Report on Renewable Energy Support in Europe. Ref: C12-SDE-33-03. Brussels.

CEER, 2015. Status Review of Renewable and Energy Efficiency Support Schemes in Europe in 2012 and 2013. Report on Renewable Energy Support in Europe. Ref: C14-SDE-44-03. Brussels

Chisari, O. and Estache, A. 1999. Winners and losers from the privatization and regulation of utilities: Lessons from a general equilibrium model of Argentina. The World Bank Economic Review.

Cubbin, S. 2006. The impact of regulatory governance and privatization on electricy industry generation capacity in developing economies. The World Bank Economic Review.

Davi-Arderius, D., Sanin, M. E., and Trujillo-Baute, E. 2017. CO2 Content of energy losses. Energy Policy, 104, 439-445.

Dickey D., and Fuller W. 1979. Distribution of the estimators for autoregressive time series with a unit root, Journal of the American Statistical Association 74; 427-431.

European Commission, 2010. An Integrated Industrial Policy for the Globalisation Era Putting Competitiveness and Sustainability at Centre Stage. Communication from the commission to the European parliament, the council, the European economic and social committee and the committee of the regions.

European Commission, 2014. Energy prices and costs report. Commission staff working document. Accompanying the document. Energy prices and costs in Europe. Communication from the commission to the European parliament, the council, the European economic and social committee and the committee of the regions. COM 2014 (21) final.

European Commission 2016. Proposal for a Directive of the European Parliament and of the Council amending Directive 2012/27/EU on energy efficiency. COM (2016) 761 final.European Commission, 2016. Clean energy for all Europeans. COM (2016) 860 final.

Filipović, S., Verbič, M., \& Radovanović, M. 2015. Determinants of energy intensity in the European Union: A panel data analysis. Energy, 92, 547-555.

Hudson, E. A. and Jorgenson, D. W. 1974. US energy policy and economic growth 1975-2000. The Bell Journal of Economics and Management Science, 461-514.

International Energy Agency (IEA). 2015. Capturing the multiple benefits of energy efficiency. 
Ozturk. A literature survey on energy-growth nexus, Energy Policy 2010; 38; 340-349.

Payne, J. 2010. Survey of the international evidence on the causal relationships between energy consumption and growth, Journal of Economic Studies 37; 53-95.

Phillips P, Perron P. 1988. Testing for a unit root in time series regression. Biometrika 75, 335346.

Pollitt. M. 2009. Electricity liberalization in the European Union: A progress report. Cambridge working papers in Economics 0953. Faculty of Economics, University of Cambridge.

Romer P. 1990. Endogenous Technological Change. Journal of Political Economy 98, 71-102.

Solow R. 1956. A contribution to the theory of economic growth. The Quarterly Journal of Economics 70, 65-94.

Stern, D. I, 1993. Energy use and economic growth in the USA, a multivariate approach. Energy Economics 15, 137-150.

Stern, D.I. 2000. A multivariate cointegration analysis of the role of energy in the US macroeconomy. Energy Economics 22, 267-283.

Stern, D.I, 2011The role of energy in economic growth. Annals of the New York Academy of Sciences 1219, 25-51. 
Table 1. The variables. Definitions and sources

\begin{tabular}{|c|c|c|}
\hline Variable & Definition & $\begin{array}{l}\text { Source } \\
\text { data }\end{array}$ \\
\hline & Equation 1 & \\
\hline $\begin{array}{l}\text { Electricity consumption } \\
\text { (Econs) } \\
\text { (dependent variable) }\end{array}$ & Final energy consumption-electricity (MWh) & Eurostat \\
\hline Economic growth (GDP) & Gross domestic product (Billions $€$ ) & Eurostat \\
\hline $\begin{array}{l}\text { RES-E promotion costs } \\
\text { (RPC) }\end{array}$ & RES-E promotion cost (€/MWh) & CEER, Own \\
\hline $\begin{array}{l}\text { Network costs -industrial } \\
\text { (NC) }\end{array}$ & $\begin{array}{l}\text { Transmission and distribution tariffs; } \\
\text { transmission and distribution losses; after- } \\
\text { sale services; system service costs and meter } \\
\text { rental. ( } € / \mathrm{MWh} \text { ) }\end{array}$ & Eurostat \\
\hline Energy cost $(E C)$ & $\begin{array}{l}\text { Wholesale Cost and Retail Margin for } \\
\text { Industrial Consumers }\end{array}$ & Eurostat \\
\hline \multirow[t]{2}{*}{$\begin{array}{l}\text { Intensive energy sectors } \\
\text { (IS) }\end{array}$} & $\begin{array}{l}\text { Energy intensive sectors activity (percentage } \\
\text { of economic activity) ( } € / \mathrm{MWh})\end{array}$ & Eurostat \\
\hline & Equation 2 & \\
\hline $\begin{array}{l}\text { Economic growth (GDP) } \\
\text { (dependent variable) }\end{array}$ & Gross domestic product (Billions $€$ ) & Eurostat \\
\hline Employment (EMP) & $\begin{array}{l}\text { Number of employees. Total economy (1000 } \\
\text { persons) }\end{array}$ & Eurostat \\
\hline Capital $(K)$ & $\begin{array}{l}\text { Net capital stock, constant prices. } \\
\text { Total economy ( } 2010 \text { prices) }\end{array}$ & Eurostat \\
\hline Productivity Trend (PT) & $\begin{array}{l}\text { Total productivity trend. Total economy } \\
\text { (Index } 2010=100 \text { ) }\end{array}$ & Eurostat \\
\hline $\begin{array}{l}\text { Electricity consumption } \\
\text { (Econs) } \\
\text { Estimated value }\end{array}$ & $\begin{array}{l}\text { Final energy consumption-electricity }(\mathrm{MWh})- \\
\text { Estimated values from first stage }\end{array}$ & Eurostat \\
\hline
\end{tabular}

Table 2. Summary statistics

\begin{tabular}{|c|c|c|c|c|c|}
\hline Variable & Observations & Mean & Std. Dev. & Min & Max \\
\hline$G D P$ & 252 & 463.92 & 700.00 & 5.96 & $2,681.59$ \\
\hline$P T$ & 224 & 101.67 & 3.91 & 92.41 & 117.52 \\
\hline$\kappa$ & 224 & $1,271.94$ & $2,177.88$ & 0.74 & $7,845.83$ \\
\hline EMP & 224 & $8,081.55$ & $10,448.78$ & 153.51 & $42,226.00$ \\
\hline Econs & 196 & $100,189,224.49$ & $134,899,234.89$ & $1,707,000.00$ & $532,424,000.00$ \\
\hline$R P C$ & 154 & 14.36 & 10.63 & 0.50 & 55.29 \\
\hline$E C$ & 180 & 68.58 & 27.88 & 26.90 & 201.20 \\
\hline$N C$ & 180 & 28.95 & 10.83 & 3.50 & 72.40 \\
\hline IS & 196 & 11.08 & 6.44 & 0.00 & 33.81 \\
\hline
\end{tabular}


Table 3. Correlation Matrix

\begin{tabular}{|l|c|c|c|c|c|c|c|c|c|}
\hline & GDP & $\boldsymbol{P T}$ & $\boldsymbol{K}$ & $\boldsymbol{E M P}$ & $\boldsymbol{E C O n s}$ & $\boldsymbol{R P C}$ & $\boldsymbol{E C}$ & $\boldsymbol{N C}$ & $\boldsymbol{I S}$ \\
\hline GDP & 1.000 & & & & & & & & \\
\hline $\boldsymbol{P T}$ & -0.092 & 1.000 & & & & & & & \\
\hline $\boldsymbol{K}$ & 0.986 & -0.095 & 1.000 & & & & & & \\
\hline EMP & 0.962 & -0.087 & 0.937 & 1.000 & & & & & \\
\hline Econs & 0.986 & -0.107 & 0.963 & 0.965 & 1.000 & & & & \\
\hline $\boldsymbol{R P C}$ & 0.271 & -0.109 & 0.315 & 0.250 & 0.267 & 1.000 & & & \\
\hline EC & 0.378 & -0.286 & 0.419 & 0.359 & 0.337 & 0.324 & 1.000 & & \\
\hline $\boldsymbol{N C}$ & -0.225 & 0.184 & -0.247 & -0.142 & -0.235 & -0.077 & -0.329 & 1.000 & \\
\hline $\boldsymbol{I S}$ & 0.122 & -0.068 & 0.110 & 0.170 & 0.171 & 0.076 & 0.233 & -0.035 & 1.000 \\
\hline
\end{tabular}


Table 4. Estimations results. First stage: Electricity consumption equation

\begin{tabular}{|l|c|}
\hline & Dep. Econs \\
\hline L.econs & $-0.225^{* * *}$ \\
\hline GDP & $(0.00880)$ \\
\hline NC & $80,457^{* * *}$ \\
\hline & $(665.1)$ \\
\hline EC & $-216,688^{* * *}$ \\
\hline & $(22,168)$ \\
\hline IS & $-51,209 * * *$ \\
\hline & $(12,946)$ \\
\hline RPC & $136,203^{* * *}$ \\
\hline & $(43,550)$ \\
\hline Constant & $-224,281^{* * *}$ \\
\hline & $(19,342)$ \\
\hline Observations & $8.194 \mathrm{e}+07^{* * *}$ \\
\hline Number of id & $(9.277 e+06)$ \\
\hline Pseudo R2 & 103 \\
\hline & 22 \\
\hline & 0.5474 \\
\hline
\end{tabular}

Table 5. Estimations results. Second stage: Growth equation

\begin{tabular}{|l|c|}
\hline & Dep. GDP \\
\hline IEMP & $0.556^{* * *}$ \\
\hline IK & $(0.0472)$ \\
\hline & $0.640 * *$ \\
\hline IEcons & $(0.0357)$ \\
\hline & $0.192 * * *$ \\
\hline PT & $(0.0558)$ \\
\hline & $0.0110 * * *$ \\
\hline Constant & $(0.000582)$ \\
\hline & $-7.474 * * *$ \\
\hline Observations & $(0.896)$ \\
\hline Number of id & 126 \\
\hline R2 & 22 \\
\hline
\end{tabular}


Table 6. Elasticities of consumption and growth to renewable energy promotion costs

\begin{tabular}{|l|c|c|}
\hline & Consumption & Growth \\
\hline Short-run Elasticity in \% & -0.032 & -0.006 \\
\hline Short-run Effect in MWh \& M€ & $-32,207$ & -28.63 \\
\hline Long-run Elasticity in \% & -0.026 & -0.005 \\
\hline Long-run Effect in MWh \& M€ & $-26,291$ & -23.37 \\
\hline
\end{tabular}

Table 7. Elasticities of consumption and growth to network costs

\begin{tabular}{|l|c|c|}
\hline & Consumption & Growth \\
\hline Short-run Elasticity in \% & -0.063 & -0.012 \\
\hline Short-run Effect in MWh \& M€ & $-62,731$ & -55.77 \\
\hline Long-run Elasticity in \% & -0.051 & -0.010 \\
\hline Long-run Effect in MWh \& M€ & $-51,209$ & -45.53 \\
\hline
\end{tabular}

\section{APPENDIX}

Table A1. Unit root tests for GDP and ECONS

\begin{tabular}{|l|c|c|c|}
\hline Variable & Statistic & ADF (p-value) & PP (p-value) \\
\hline GDP & Inverse Chi-squared & $2,65628 \mathrm{E}-09$ & 0,007609123 \\
\hline & Inverse Normal & $2,832 \mathrm{E}-06$ & 0,009314395 \\
\hline & Inverse Logit & $7,03071 \mathrm{E}-08$ & 0,008937038 \\
\hline Econs & Modified inv. chi-squared & $4,44089 \mathrm{E}-16$ & 0,003151377 \\
\hline & Inverse Chi-squared & $2,32213 \mathrm{E}-38$ & $3,63143 \mathrm{E}-18$ \\
\hline & Inverse Normal & $1,89146 \mathrm{E}-14$ & $5,05593 \mathrm{E}-09$ \\
\hline & Inverse Logit & 0 & $4,26326 \mathrm{E}-14$ \\
\hline
\end{tabular}

